\title{
Portal de periódicos científicos: um trabalho multidisciplinar
}

\author{
Portal of scientific journals: a multidisciplinary work
}

Rosângela Schwarz RODRIGUES'

Gleisy Regina Bories FACHIN 2,3

\section{RESUMO}

Este artigo descreve a implementação de um portal de periódicos científicos institucional. Apresenta lista de verificação para migração de periódicos científicos para plataforma de editoração, nesse caso o Sistema Eletrônico de Editoração de Revistas - Open Journal Systems. Resgata a importância dos projetos de extensão e sua integração com projetos de pesquisa e a capacitação de bolsistas, bibliotecários, editores e professores. Conclui destacando a importância dos periódicos científicos digitais e sua padronização e sistematização em portais, além de demonstrar a necessidade de um trabalho multidisciplinar e detalhar o processo de migração de periódicos e a estrutura necessária.

Palavras-chave: Portal de periódicos científicos. Acesso aberto. Open journal systems.

\section{A B S T R A C T}

This article describes the implementation of an institutional portal of academic journals. Presents a checklist for migration to scientific journals publishing platform, the Electronic System for Journal Publishing - Open Journal Systems. Discuss the importance of the extension projects and their integration with research projects and training of students, librarians, editors and professors. Concludes by highlighting the importance of digital journals and their standardization and systematization in portals, as well as demonstrating the need for multidisciplinary team work and the migration process and the structure involved.

Keywords: Scientific journal portal. Open access. Open journal systems.

\section{NTRODUÇÃ O}

A evolução das sociedades chamadas da informação e do conhecimento tem levado governantes a buscar recursos e soluções para atender às demandas educacionais, científicas e tecnológicas da comunidade acadêmica, cada dia mais exigente quanto à precisão e relevância das informações governamentais, empresariais e industriais, além da área educacional,

1 Professora Doutora, Universidade Federal de Santa Catarina, Programa de Pós-Graduação em Ciência da Informação e do Departamento de Ciência da Informação. Campus Universitário, Trindade, 88010-970, Florianópolis, SC, Brasil. Correspondência para/Correspondence to: R.S. RODRIGUES. E-mail: <rosangela@cin.ufsc.br>.

2 Doutoranda, Universidade Federal de Santa Catarina, Programa de Pós-Graduação em Engenharia e Gestão do Conhecimento. Florianópolis, SC, Brasil.

3 Professora, Universidade Federal de Santa Catarina, Departamento de Ciência da Informação. Florianópolis, SC, Brasil. Recebido em 15/11/2009 e aceito para publicação em 8/4/2010. 
científica e tecnológica (Willinsky, 2006; Kuramoto, 2008; Rodrigues; Fachin, 2008).

Nesse contexto, tem-se a comunicação científica, e, em especial, os periódicos científicos on-line, que permitem o acesso ao conhecimento referenciado e validado a comunidade em geral. Discute-se se tal acesso é livre ou restrito em todas as áreas do conhecimento, envolvendo inúmeros setores, quer de áreas específicas ao tratamento e disseminação da informação quer de áreas correlatas.

Como organizar, tratar, disponibilizar, recuperar e preservar informações científicas é uma discussão a descoberto, fortemente influenciada pela evolução das Tecnologias de Informação e Comunicação (TIC). São várias as informações coletadas sobre a organização de periódicos científicos e, conforme esclarece Bräscher (2007, p. 12), a "área da comunicação científica sente os impactos dos novos recursos informacionais, pois é exatamente no contexto da comunicação científica que ocorrem as maiores mudanças provocadas pelas tecnologias da informação e da comunicação". Ainda ao citar Mikhailov et al. (1980) citado por Bräscher, (2007, p. 12) comenta que "a tecnologia nunca foi e, também não é hoje o principal fator determinante do desenvolvimento na esfera da comunicação científica", pois as maiores descobertas das TIC, a "exemplo da imprensa e da automação do processamento da informação, determinam a mudança de nível de comunicação em cada época". Ou seja, desde os primórdios da história, a informação científica está presente e muda acompanhando a própria evolução do homem, a quem cabe incorporar as novas versões tecnológicas.

Nesse aspecto, o estudo, pesquisa, criações e adaptações são realizados a fim de melhor disponibilizar e recuperar informações em periódico científico, sempre atendendo os aspectos evolutivos de cada época. Com todo o ferramental disponível com as TIC, para Bräscher (2007, p. 13), "o ambiente web não dispõe dos recursos de seleção, organização e recuperação que os ambientes das bases de dados oferecem. As dificuldades de acesso a informações relevantes são conhecidas dos usuários da web".

Assim, este artigo relata a criação de portal para periódicos científicos, destacando questões como recursos humanos e materiais e as pesquisas associadas ao projeto, além de dar ênfase ao aspecto de padronização, da adoção de normas e ao processo de institucionalização. Apresenta uma lista de verificação elaborada para sistematizar o fluxo de migração dos periódicos para o portal.

\section{PERIÓDICO CIENTÍFICO: ACESSO LIVRE}

Mueller (2006) discute que o sistema de comunicação científica é a infraestrutura da comunidade científica. O periódico científico é o veículo disseminador da produção científica em determinada área do conhecimento e são essas áreas que se organizam e se estruturam para criar, manter, disseminar e preservar suas informações. É no periódico científico que o conhecimento pode ser disseminado de forma mais atualizada e confiável em função da periodicidade e dos rigorosos processos de revisão pelos pares.

Os benefícios da informação científica e acadêmica, em formato on-line e em acesso livre, e com a necessária credibilidade, vão além do aumento de citações em pesquisas. Willinsky (2006) discute a disponibilidade de resultados confiáveis nesse novo formato - on-line -, que não privilegia apenas os pesquisadores no sentido de não precisarem sair da frente de seus computadores e visitarem uma biblioteca, mas que ajuda os pesquisadores a traçarem um fluxo de idéias de artigo em artigo, dentro de um círculo de citações e referências cruzadas, permitindo um acesso mais sofisticado às informações.

Población et al. (2006) resgatam, desde o surgimento da informação científica, reconhecida como tal, o aparecimento das primeiras sociedades científicas e os primeiros periódicos científicos em formato impresso e que evoluíram para o formato on-line. Nessa obra, os autores discutem a informação científica na sucessão de diferentes formas e o uso de tecnologias no transcorrer dos anos. A criação, organização, tratamento, disseminação e preservação dessas informações são qualificadas com ênfase na inter-relação entre as $\mathrm{TICe}$ o fluxo da comunicação científica. Na visão de Weitzel (2006, p.83) a comunicação científica "remonta ao período da antiguidade, quando os filósofos estabeleciam amplos debates sobre suas idéias na chamada Academia". Dessa forma, os primeiros formatos de informação científica se faziam presentes e, segundo a autora, o "processo de acumulação de conhecimento envolve trocas de informações para fomentar novo conhecimento e para isso, além da acumulação, é necessária a divulgação desse

TransInformação, Campinas, 22(1):33-45, jan./abr., 2010 
conhecimento de uma 'forma durável e prontamente acessível'". Acrescenta-se a necessidade de preservação dessas informações, aspecto igualmente discutido.

A questão da preservação digital também é discutida por Márdero Arellano (2008, p.44) quando afirma que essa é a

Parte mais longa e também a última do ciclo de gerenciamento de objetos digitais. Ela permite o emprego de mecanismos que viabilizam o armazenamento em repositórios de objetos digitais e que garantem a autenticidade e perenidade dos seus conteúdos. São necessários, não apenas, procedimentos de manutenção e recuperação de dados, no caso de perdas acidentais para resguardar a mídia e seu conteúdo, mas também estratégias e procedimentos para manter sua acessibilidade e autenticidade através do tempo, podendo requerer colaboração entre diferentes financiadoras e boa prática de licenciamento, metadados e documentação, antes de aplicar ações técnicas.

Desse modo, percebe-se que informação científica e periódico científico são congruentes e envolvem uma gama de estudos e pesquisadores de áreas multidisciplinares, da mesma forma que são inúmeros os recursos tecnológicos disponíveis para a coleta, organização, tratamento, disseminação e preservação de periódico científico.

Na evolução histórica dos periódicos científicos, várias são as definições e recursos utilizados, desde sua criação até a disseminação e preservação. Gruszynski e Golin (2006, p. 1) afirmam que periódico científico é a instância de consagração no processo da comunicação científica, pois, ao "atuar como um filtro seletivo, reproduzindo as sanções e exigências próprias do campo científico, confere valor às pesquisas e as situa no seu grau de originalidade em relação ao conhecimento já acumulado em determinada área do conhecimento".

Corroborando com as autoras acima citadas, Marchiori e Adami (2005), após pesquisa realizada envolvendo docentes pesquisadores de uma universidade federal, relatam que o modelo ideal de periódico poderia ser um instrumental qualitativo, pois, segundo seus estudos, garantiria à memória da ciência, o grau de evolução, a propriedade intelectual, além de legitimar novos campos de estudos e disciplinas. Desse modo, constitui-se em fonte para o início de novas pesquisas, dando visibilidade e prestígio aos pesquisadores entre um público altamente especializado, que são os pareceristas e os avaliadores dos periódicos. Contribuindo nessa linha, estudiosos da área como Meadows (2001), Lemos (2005), Leite e Costa (2006), Mueller (2006), Stumpf (2006), Willinsky (2006), Harnad (2007), Bailey Jr. (2008), Costa (2008), Cunha (2008), Ferreira e Targino (2008), e Medeiros et al. (2008) que discutem, compilam e apresentam desde a evolução dos periódicos científicos, suas várias definições no transcorrer dos anos e sua adequação às mudanças tecnológicas, acabam por contribuir com a definição de periódicos científicos, que são todos ou quaisquer tipos de publicação editada em números ou fascículos independentes - não importando a sua forma de edição, ou seja, seu suporte físico (papel, CD-ROM, bits, on-line, digital), mas que tenham um encadeamento sequencial e cronológico - e seja editada, preferencialmente, em intervalos regulares, por tempo indeterminado, atendendo às normalizações básicas de controle bibliográfico universalmente reconhecido, trazendo a contribuição de vários autores, sob a direção de uma pessoa ou mais (editor), de preferência uma entidade responsável (maior credibilidade). Poderá, igualmente, tratar de assuntos diversos (âmbito geral) ou de ordem mais específica, cobrindo uma determinada área do conhecimento, mas que deverá apresentar a maioria (+ de 50\%) de seu conteúdo em artigos científicos, ou seja, artigos assinados oriundos de pesquisas, identificando métodos, resultados, análises, discussões e conclusões, bem como, disponibilizar citações e referências, comprovando os avanços científicos (Fachin et al., 2006).

Ainda nesse contexto, Meadows (2001) afirma que os periódicos eletrônicos necessitam seguir as rotinas que sinalizam o seu reconhecimento, reputação e credibilidade em sua área de atuação, pois, cada vez mais, o ambiente digital dificulta a distinção entre comunicações formais e informais. Para Biojone (2003), a grande quantidade de informações, perdida pelo processo de arbitragem, ou de textos que seriam submetidos a avaliações posteriores, abalam um dos principais pilares de confiabilidade no processo formal de comunicação entre pesquisadores - a revisão pelos pares, em sua área de atuação, o que valida a informação científica. 
Assim, a quantidade de informações na web forma um ambiente caótico, onde recuperar informações torna-se mais difícil e a relevância e precisão são quase nulas, embora os sistemas de indexação e recuperação de informações estejam cada dia mais sofisticados. Já para Baptista e Machado (2001 , p.78) para

\begin{abstract}
Melhorar a eficácia e a eficiência dos serviços de informação, torna-se necessária a utilização de metadados semânticos. No entanto, com a utilização de diferentes metadados e estruturas de metadados pelos diversos tipos de serviços e software, o problema mantém-se. Conforme acontece noutras áreas, a padronização é um elemento chave para a utilização eficaz dos metadados.
\end{abstract}

Café e Bräscher (2008, p.68) analisam a questão da falta de padronizações que existe nos periódicos, quando realizam pesquisas e constataram dificuldades na

\begin{abstract}
Análise de citação no que se refere à descrição bibliográfica, mais especificamente, aquelas relativas à padronização de títulos de periódicos e nomes de autores. Os problemas de descrição de conteúdo dizem respeito à representação de assunto nas bases de dados ou outras fontes utilizadas para a coleta dos documentos que compõem o corpus de pesquisa.
\end{abstract}

Percebe-se que são muitos os recursos que despontam como soluções para as informações científicas digitais. Ênfase se dá para as TIC que eclodiram nos últimos anos, possibilitando as diversas áreas do conhecimento: criar, organizar e circular periódicos, nas mais diferentes formas, padrões e suportes, promovendo um aumento exponencial de publicações, muitas das quais de forma isolada e que não permitem buscas integradas entre si, tornando a recuperação da informação ainda mais ineficaz.

Universidades e pesquisadores têm especial interesse em aumentar, preservar e disseminar os artigos que produzem, pois são ferramentas imprescindíveis para discussões acadêmicas e tomadas de decisão, tanto pelos próprios pesquisadores em relação à continuidade e direcionamento de suas pesquisas, quanto pelas instituições de fomento da pesquisa, para uso em processos de avaliação de produção científica e consolidação de áreas (Marchiori; Adami, 2005; Leite; Costa, 2006; Costa, 2008). Ainda nesse contexto, Harnad (2007, p. 1 1), discorre sobre a importância dos artigos científicos, pois, o que torna

\begin{abstract}
Artigos de revista especiais é que eles são, e sempre têm sido, entregues gratuitamente por seus autores (aos editores, aos solicitantes de reimpressão). Esses artigos não foram escritos com fins lucrativos. Eles foram escritos para maximizar o seu uso, entendimento, aplicações e impacto. Isto é, como pesquisadores contribuem para o incremento do conhecimento, e o impacto de sua pesquisa é também um fator determinante do financiamento de sua pesquisa, dos seus salários e da sua carreira.
\end{abstract}

Nesse contexto, onde se discute o desenvolvimento da informação científica, seus custos, seus investimentos, padrões, controle e garantia de preservação é que aparecem modelos alternativos de comunicação científica, como a organização de publicações coletivas em portais e repositórios digitais, podendo ser temáticos ou institucionais, além dos sites específicos de cada periódico ou as bibliotecas digitais, e esses recursos vêm crescendo exponencialmente, na razão direta do barateamento e desenvolvimento de aplicativos digitais para a internet.

Cabe ressaltar, ainda, a importância de periódicos disponíveis em qualquer formato ou suporte, e que a avaliação pelos pares, dentro da área de atuação, é um dos critérios que mais distingue os periódicos científicos de qualquer outro tipo de publicação. Esse aspecto diferencia também um portal de periódicos científicos de um repositório institucional ou temático. Isso pode ser largamente observado em revistas não científicas, em sites, blogs ou twitter, onde a revisão de pares é inexistente ou opcional, onde o importante é divulgar, discutir e disseminar.

Stumpf (2006, p.21) ressalta que a presença do sistema de arbitragem ou pela revisão pelos pares (referee system ou peer review) é o fator que distingue o grau de confiabilidade das publicações científicas. Nesse contexto, os avaliadores chamados como "consultores, pareceristas ou árbitros [...], são as pessoas que julgam os originais enviados pelos editores. Embora exerçam uma atividade que pode estar carregada de subjetividade, espera-se deles que realizem comentários justos que adotem o valor e a 
contribuição daquele trabalho para o desenvolvimento da ciência". Complementa a autora que esses mesmos revisores pontuem possíveis falhas, erros, incorreções nas discussões e que auxiliem os autores a melhorarem seus artigos.

Mueller (2006, p.34), também contribui ao colocar que "parece estar claro, hoje, que qualquer iniciativa de publicação científica que não garanta avaliação prévia dos conteúdos por especialistas vai encontrar muitas barreiras para ser 'legitimada' no mesmo nível dos periódicos tradicionais", o que faz surgir uma preocupação com a confiabilidade da publicação de artigos e sua contribuição para as áreas científicas.

A evolução dos mecanismos de comunicação associados às tecnologias e sua aceitação cada vez maior incorporada pelas pessoas minimizam a discussão sobre a qualidade dos periódicos on-line, que passam a serem classificados, cada vez mais, de acordo com suas características científicas, técnicas e validados por seus pares, do que pelo tipo de suporte que usam.

movimento de acesso livre, somado aos recursos dos arquivos abertos, vem modificar e interferir de forma significativa no processo da comunicação científica e na divulgação de periódicos científicos (Costa, 2008). O movimento de acesso livre às informações, na opinião de Harnad (2007, p.10) objetiva a divulgação dos resultados de "pesquisa científica e acadêmica publicados em revistas com revisão pelos pares [...] para todos os potenciais usuários da web, a fim de maximizar o acesso aos resultados de pesquisa, uso, aplicações, impacto, e consequentemente, a produtividade na pesquisa e o progresso".

Willinsky (2006) considera o atual movimento de acesso ao conhecimento um paralelo nas ações de extensão das universidades do século XIX, as quais deram origem às Universidades Abertas estabelecidas no século XX, possibilitando, assim, um maior acesso, que, segundo o referido autor, está na crença de que esses movimentos permitem o acesso à informação acadêmica de alta confiabilidade e relevância, em proporções maiores, para uma parcela mais significativa da população.

A questão do acesso livre à comunidade científica por meio do ambiente on-line envolve muito mais do que questões políticas ou de normalizações, mas sim questões de costumes, diferentes culturas e hábitos, tanto no cotidiano como em pesquisa em cada comunidade científica e/ou acadêmica, estando a questão tecnológica presente em todos os argumentos.

Para Ferreira e Targino (2005), Leite e Costa (2006), Bailey Jr. (2008), Costa (2008), Ferreira (2008), os repositórios e os portais institucionais ganharam força devido ao movimento de acesso livre, gerando mudança na indústria de publicação científica. Desde suas primeiras implementações, os repositórios e/ou portais têm sido voltados para a informação científica.

crescimento da importância dos periódicos científicos como instrumento de avaliação dos programas de pós-graduação aumenta o interesse das instituições de ensino na manutenção e qualificação dos periódicos vinculados à organização, especialmente os de acesso livre e com arquivos abertos, e gera novas questões organizacionais cujos estudos apenas se iniciam. A própria Coordenação de Aperfeiçoamento de Pessoal de Nível Superior (CAPES) recomenda que os periódicos adotem práticas e normas internacionais, indicando, inclusive, sistemas brasileiros de editoração eletrônica que obedeçam aos padrões internacionais, o que propicia o reconhecimento dos títulos e aumenta a visibilidade da produção científica brasileira.

E diante dessa realidade, há o desafio de estruturar o planejamento e os custos associados à editoração científica em meio digital, bem como a preservação dos arquivos e questões culturais das instituições. A organização de vários periódicos, de uma mesma instituição em um Portal, requer diversas ações integradas como: estrutura organizacional para viabilizar as ações de migração para a plataforma adotada; alocação de recursos para custos associados; definição da responsabilidade institucional para com o grupo de periódicos, que tende a se configurar como uma "meta-editora". Sendo assim, o portal é composto por vários editores de periódicos científicos de diversas áreas do conhecimento e cada um com suas especificidades. (Rodrigues; Fachin, 2008).

Os periódicos científicos sofrem forte influência da tecnologia em todo o processo. A questão do acesso livre implica novos arranjos institucionais para garantir aos editores, suporte e segurança no processo de migração para a plataforma de arquivos abertos e o refinamento das edições subsequentes aos recursos disponibilizados. A movimentação em torno da tecnologia mantém a preocupação essencial com a 
confiabilidade e legitimidade das publicações, que é garantida pela revisão dos pares.

\section{PORTAL PERIÓDICOS CIENTÍFICOS}

○ uso de portais permite a integração, colaboração e personalização baseadas na utilização de recursos das $\mathrm{TIC}$ e da Web. Complementa-se, ainda, o conceito de portal, segundo Baroni (2005), quando discorre que "portal é uma plataforma tecnológica que permite que os trabalhadores do conhecimento acessem e compartilhem informações, tomem decisões e realizem ações independentemente da sua localização física, do formato da informação e do local em que ela está armazenada". Assim, o portal diz respeito à integração de sistemas, exigindo trabalho inovador e interdisciplinar de infraestrutura da equipe de TIC, de colaboradores, autores, além da comissão que o gerencia.

Essa forma inovadora de disseminar as produções científicas, segundo Rodrigues et al. (2007), e Costa (2008) e, sejam repositórios ou portais institucionais, armazenam, preservam, divulgam e dão acesso à produção intelectual de comunidades universitárias e/ou de um grupo específico de instituições ou pessoas. Esses portais intervêm em duas questões estratégicas: contribuem para o aumento da visibilidade e do valor público das instituições, servindo como indicador tangível da sua qualidade, e contribuem para o sistema de comunicação científica, expandindo o acesso aos resultados da investigação e assumindo o apoio aos editores e a responsabilidade da disseminação e preservação dos periódicos da instituição.

Oapoio explícito de agências de fomento e de avaliação da produção científica, das quais, no Brasil, destacam-se a CAPES, o Conselho Nacional de Desenvolvimento Científico e Tecnológico (CNPq) e o Instituto Brasileiro de Informação, Ciência e Tecnologia (IBICT) são de fundamental importância para a aceitação do modelo de arquivos abertos pela comunidade científica. Em contrapartida, o apoio interno da instituição que está implantando um portal deverá ser aceito em sua plenitude e incorporado por todos os setores envolvidos. $\bigcirc$ ideal é a institucionalização do portal pela alta direção e pela comunidade científica, pois o aceite dos envolvidos e a criação de uma estrutura para as instalações físicas (equipamentos e espaços) e de pessoal são essenciais, pois, sem eles, não é possível manter o portal ativo 24 horas e os sete dias da semana.

Otrabalho de organização do portal, seus objetivos e políticas deveriam ser informados para o público da instituição, obedecendo a um cronograma lógico e efetivo em cada etapa a ser implantada, como: oferta de cursos de editoração científica para a plataforma adotada a editores e demais envolvidos; reuniões abertas com todos os editores, com imprescindível presença da gerência e da diretoria, as quais garantem a importância do projeto e o apoio da instituição.

A Figura 1, mostra a estrutura básica necessária para o projeto e a criação de um portal de periódicos científicos, nesse caso de acesso livre e arquivos abertos. Segundo experiência relatada por Rodrigues e Fachin (2008), essa estrutura é essencial para a implantação de um portal que atenda aos critérios gerais de reconhecimento na área da comunicação científica e/ ou em diferentes áreas do conhecimento.

Diante dessa estrutura, alerta-se ainda para a quantidade de periódicos a serem incluídos na plataforma, que requer o cumprimento de cronogramas, reuniões permanentes e a existência de uma equipe capacitada e preparada para o atendimento aos editores e para a implantação do portal. Segundo Rodrigues e Fachin (2008), a existência de uma "incubadora de periódicos" é o ideal para a preparação de novos periódicos antes de seu ingresso no portal. Isso se justifica pelo fato de que o portal de periódicos deve atender aos critérios de validação da informação científica. $\bigcirc$ fato de os periódicos estarem em um portal apenas otimiza os recursos materiais e humanos, mas o teor de cada publicação fica a cargo dos editores, sob a responsabilidade de sua equipe editorial. Conforme Mueller (2006), Stumpf (2006), Trzesniak (2006), Harnad (2007), o fato de os periódicos estarem em formato digital e/ou reunidos em um portal não elimina o processo de revisão pelos pares.

Na Figura 2, a seguir, apresenta-se o fluxo de trabalho e os agentes envolvidos no processo da migração de periódicos científicos para um Portal em implantação. Destaca-se que o contato entre os participantes deve ser constante e o feedback dos periódicos com a equipe técnica e coordenação do Portal é essencial para a evolução dos trabalhos e a obtenção de resultados positivos. 
1 - Pesquisa bibliográfica

a) Comunicação científica

b) Periódicos com acesso livre e arquivos abertos

c) Recursos tecnológicos a serem adotados

d) Institucionalização do Portal

\section{2 - Recursos humanos}

a) Equipe técnica interdisciplinar do Portal

(migração, padronização, conferência, segurança)

b) Editores e equipe editorial de cada periódico

c) Dirigentes da instituição

d) Instituições de Fomento e Avaliação

\section{3 - Agentes consultados (atores constantes no processo)}

a) Editores

b) Equipe técnica (colaboradores, alunos, usuários em potencial)

c) Coordenação do Portal

d) Dirigentes institucionais

e) Comunidade em geral (professores, alunos e demais usuários)

\section{4 - Modelo proposto}

a) Equipe multidisciplinar (design, analistas de sistema, segurança e preservação)

b) Diretrizes do Portal e políticas institucionais

c) Manutenção

Figura 1. Estrutura básica para implantação de um portal de periódicos científicos.

Fonte: Adaptado de Rodrigues e Fachin (2008).

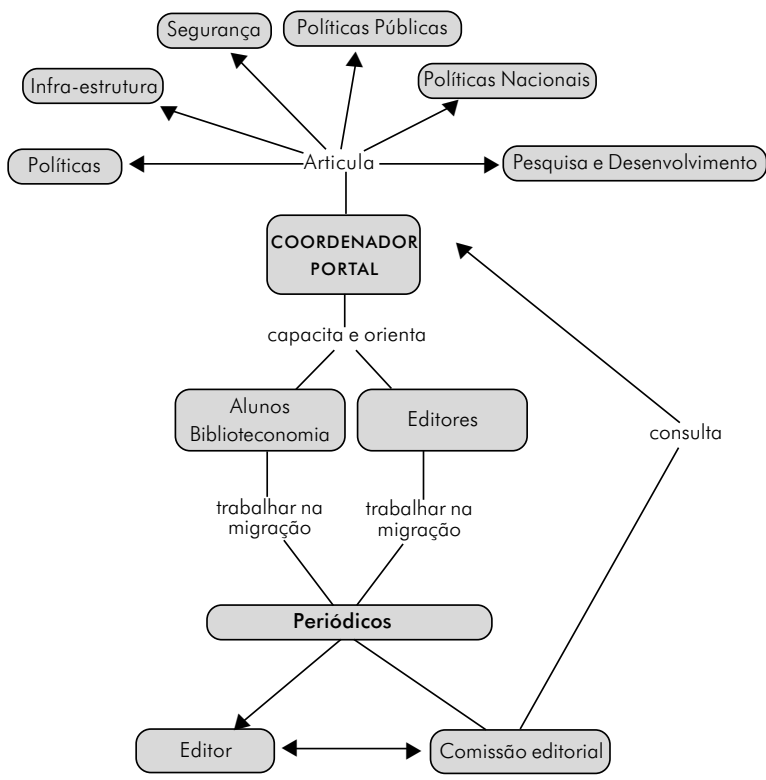

Figura 2. Modelo de fluxo de trabalho para portais de periódicos.

Fonte: Rodrigues e Fachin (2008).
Observa-se, na Figura 2 que a implementação exige uma estrutura complexa, que deverá ser instituída, aprovada e divulgada à comunidade envolvida. Só assim as ações poderão ser alcançadas e realizadas. Na experiência relatada por Rodrigues e Fachin (2008), foram apresentados três tipos de ações, a saber: a) formação e capacitação de editores e alunos bolsistas; b) organização das questões técnicas e operacionais; e c) supervisão dos trabalhos, garantindo a precisão das informações e dos detalhes dos periódicos. Baseando-se nesses aspectos e, transcorridos 12 meses, adapta-se e incrementa-se para cinco ações:

1) Apresentação e aprovação do Projeto do Portal pela instituição, considerando a estrutura básica apresentada na Figura 2;

2) Formação e capacitação constante da equipe técnica, editores e demais envolvidos no processo do portal, em função dos recursos tecnológicos adotados e implantados;

TransInformação, Campinas, 22(1):33-45, jan./abr., 2010 
3) Estruturação e organização das questões técnicas e operacionais que envolvem todo o processo de implantação do portal. Recomenda-se a adoção de uma lista de verificação para migração, elaborado e validado na implantação do Portal de Periódicos da UFSC (Apêndice A);

4) Avaliação e conferência da migração de cada periódico aprovado, garantindo a adoção de padrões e das políticas adotadas;

5) Acompanhamento e reuniões frequentes para a socialização dos resultados.

É essencial a definição dos objetivos e as políticas para o portal, em concordância com o perfil da instituição e sua comunidade. Muitos exemplos de objetivos e políticas podem ser consultados, entre eles: Portal de Periódicos e Repositórios de Acesso Livre Oásis Brasil, do IBICT <http://oasisbr.ibict.br/>; Scientific Electronic Library Online (SciELO) < http:// www.scielo.br/>; Sociedade Brasileira de Estudos Interdisciplinares da Comunicação (INTERCOM) < http:/ /www.intercom.org.br/>, entre outros.

Complementa-se que a adoção de normas e padrões é crucial, pois possibilita a interoperabilidade entre os sistemas adotados, e todas essas ações devem ser conhecidas e dominadas pelos editores de cada um dos periódicos que irão fazer parte do portal, conforme discute Fachin et al. (2006, p.230), que

Gerenciamento editorial de cada periódico ficaria sob a responsabilidade do centro ou departamento ou programa que edita a revista. Cabe ressaltar que a padronização dos metadados e demais requisitos básicos de cada periódico e a sua busca pela indexação dos mesmos, em suas áreas específicas, ficam a encargo de cada periódico.

A organização de periódicos em Arquivos Abertos e Acesso Livre em instituições públicas responde ao incentivo das agências governamentais, especialmente as vinculadas aos programas de pós-graduação. A iniciativa de criar um portal que reúne todos os periódicos da instituição possibilita otimizar as ações em duas frentes principais: a) a capacitação e atualização dos editores, bibliotecários e bolsistas e demais envolvidos no uso da plataforma adotada; e b) criação e manutenção da estrutura tecnológica que garante a preservação dos arquivos, o que torna a instituição responsável pela segurança digital de todos os periódicos.

Para auxiliar no planejamento do processo de migração e avaliação dos periódicos, foi elaborado o check list apresentado no Anexo.

As questões relacionadas com a padronização também são beneficiadas, pois, como todos os periódicos podem ser vistos por todos os editores, a adoção das normas por um periódico serve de modelo para os demais, o que tem sido utilizado com frequência nas reuniões com grande aceitação por parte dos editores. A questão das normas deve ser claramente expressa em documento institucional amplamente divulgado e facilmente acessível. A criação de um Conselho Editorial para o Portal garante o atendimento às diretrizes, que são publicadas no próprio site do portal (http://repositório.periódicos.ufsc.br/ diretrizesportal/versãofinal.pdf) e explicam a opção por acesso livre e o compromisso com a interoperabilidade internacional.

\section{CONSIDERAÇÕES FINAIS}

Organizar periódicos científicos em arquivos abertos e de acesso livre, tendo a filiação institucional como elemento aglutinador, gera novos e complexos arranjos organizacionais, contrariando o discurso corrente de que os periódicos de acesso livre em plataformas de arquivos abertos são de rápida, fácil e barata implementação.

Criar uma estrutura para viabilizar a migração de periódicos e manter os padrões técnicos (equipamentos, acesso em tempo real, segurança, preservação) e científicos (validação, visibilidade, indexação) demanda esforços, na maioria das vezes, de forma voluntária, de professores, servidores técnico-administrativos e alunos qualificados e com múltipla formação. Além disso, requer esforços para garantir o suporte da alta direção, que precisa entender o projeto como relevante, aceitá-lo e institucionalizá-lo plenamente, o que permitirá a sua continuidade sem contratempos, mesmo após mudanças na alta direção.

portal de periódicos, que se iniciou como um projeto de extensão de professores do Departamento de Ciência da Informação, passa para a gestão da Biblioteca Central, um ano após o lançamento, com a 
presença de 37 periódicos. Destes, 22 completaram a fase de migração e passaram a utilizar a plataforma para realizar o processo de editoração completa e totalmente on-line.

Agrupar periódicos científicos de diversas áreas do conhecimento, cada qual com suas particularidades, em um portal institucional, requer articulação permanente do grupo envolvido no projeto. A colaboração de agentes com múltiplas atuações é requisito essencial para a obtenção de resultados positivos, tendo-se o entendimento de que o foco é o suporte ao editor do periódico, elemento central no processo editorial e conhecedor dos reais objetivos do periódico, por meio do qual é possível a adequação e implementação das normas e diretrizes do portal.

\section{Agradecimentos}

Este trabalho só foi possível com a colaboração de Káthia Regina Lemos Jucá (Núcleo de Processamento de Dados/UFSC) e da Profa. Ursula Blattmann (CIN/ PGCIN/UFSC).

\section{REFERÊNCIAS}

BAILEY JR., C.W. Scholarly electronic publishing bibliography: SEPB. 2008 Annual Edition. Available from: < http://www.digitalscholarship.org/sepb/sepb.html>. Cited: 21 May 2008.

BAPTISTA, A.A.; MACHADO, A.B. Um gato preto num quarto escuro: falando sobre metadados. Revista de Biblioteconomia de Brasília, v. 25, n. 1, p.77 - 90, 2001.

BIOJONE, M.R. Os periódicos científicos na comunicação da ciência. São Paulo: Educ/Fapesp, 2003.

BRÄSCHER, M. Prefácio. In: GIANNASI-KAIMEN, M.J.; CARELLI, A.E. (Org.). Recursos informacionais para compartilhamento da informação: redesenhando acesso, disponibilidade e uso. Rio de Janeiro: E-Papers, 2007. p. 9-13.

CAFÉ, L.; BRÄSCHER, M. Organização da informação e bibliometria. Encontros Bibli: Revista Eletrônica de Biblioteconomia e Ciência da Informação, (Especial), p.54-75, 2008.

COSTA, S. Abordagens, estratégias e ferramentas para o acesso aberto via periódicos e repositórios institucionais em instituições acadêmicas brasileiras. Liinc em Revista, v.4, n.2, p.218-232, 2008.

CUNHA, M.B. Das bibliotecas convencionais às digitais: diferenças e convergências. Perspectivas em Ciência da Informação, v. 13, n. 1, p. 2-17, 2008

FACHIN, G.R.B.; HILLESHEIM. A. Periódico científico: padronização e organização. Florianópolis: Editora da UFSC, 2006.

FACHIN, G.R.B. et al. Relato do Simpósio de Comunicação Científica: desafios da inclusão digital. Encontros Bibli: Revista Eletrônica de Biblioteconomia e Ciência da Informação, n. 22, 2006.

FERREIRA, S.M.S.P.; TARGINO, M.G. (Org.). Preparação de revistas científicas: teoria e prática. São Paulo: Reichmann/Autores, 2005

FERREIRA, S.M.S.P.; TARGINO, M.G. (Org.). Mais sobre revistas científicas: em foco a gestão. São Paulo: Editora Senac, 2008.

GRUSZYNSKI, A.C.; GOLIN, C. Periódicos científicos nos suportes impresso e eletrônico: apontamentos para um estudo-piloto na UFRGS. Revista de Economía Política de las Tecnologías de la Información y Comunicación, v. 8, n. 2, 2006.

HARNAD, S. Entrevista sobre arquivos aberto e acesso. [Entrevistadores: Lígia Café a Hélio Kuramoto. Encontros Bibli: Revista Eletrônica de Biblioteconomia e Ciência da Informação, (número especial), 2007.

KURAMOTO, H. Acesso livre à literatura científica: mitos e verdades. In: CONFERÊNCIA IBERO-AMERICANA DE PUBLICACÕES ELETRÔNICAS NO CONTEXTO DA COMUNICAÇÃO, 2., 2008, Rio de Janeiro. Anais ... Disponível em: < http:/ /cipecc2008.ibict.br/index.php/CIPECC2008/cipecc2008/paper/ view/21/41 >. Acesso em: 10 jun. 2009.

LEITE, F.C.; COSTA, S.M.S. Repositórios institucionais como ferramenta de gestão do conhecimento científico no ambiente acadêmico. Perspectivas em Ciência da Informação, v. 11, p. 206 $219,2006$.

LEMOS, A.B. Periódicos eletrônicos: problema ou solução? In: ENCONTRO NACIONAL DE EDITORES CIENTÍFICOS, 10., 2005, São Pedro. Disponível em: <http://www.briquetdelemos.com.br/ briquet/briquet_lemos7.html >. Acesso em: 10 jan. 2009.

MÁRDERO ARELLANO, M.Á. Critérios para a preservação digital da informação científica. 2008. 354f. Tese (Doutorado em Ciência da Informação) Universidade de Brasília, Brasília, 2008.

MARCHIORI, P.Z.; ADAMI, A. Autoria e leitura de artigos por docentes pesquisadores: motivações e barreiras. In: FERREIRA, S.M.S.P.; TARGINO, M.G. Preparação de revistas científicas: teoria e prática. São Paulo: Reichmann \& Autores, 2005. p.73-100. 
MEADOWS, A.J. Os periódicos científicos e a transição do meio impresso para o eletrônico. Revista de Biblioteconomia de Brasília, v. 25, n. 1, p. $5-14,2001$

MEDEIROS, G.M.; FACHIN, G.R.B.; RADOS, G.J.V. Padronização de periódicos científicos on-line da área de Biblioteconomia e Ciência da Informação: adequação as normas ISO. Revista ACB: Biblioteconomia em Santa Catarina, v. 13, n.2, p.415-438, 2008

MUELLER, S.P.M. A comunicação científica e o movimento de acesso livre ao conhecimento. Ciência da Informação, v. 35, n. 2, p. 27-38, 2006.

POBLACIÓN, D.A.; WITTER, G.P.; SILVA, J.F.M. (Org.). Comunicação e produção científica: contexto, indicadores e avaliação. São Paulo: Angellara, 2006.

RODRIGUES, E. et al. Repositório: criação e desenvolvimento do Repositório Institucional da Universidade do Minho. 2007. Disponível em: <http://eprints.rclis.org/archive/00007962/01/ BAD artigo - Final.pdf >. Acesso em: 30 maio 2008.
RODRIGUES, R.; FACHIN, G. R. B. A comunicação científica e o uso de portais: estudo. In: ENCONTRO NACIONAL DE PESQUISA EM CIÊNCIA DA INFORMAÇÃO - ENANCIB, 9., 2008, Rio de Janeiro. Anais... Rio de Janeiro. ENANCIB; 2008. 1 CDROM.

STUMPF, I.R.C. Revisão pelos pares: do tradicional ao inovador. In: CONFERẾNCIA IBEROAMERICANA DE PUBLICAÇÕES ELETRÔNICAS NO CONTEXTO DA COMUNICAÇÃO CIENTÍFICA, 1., 2006, Brasília. Anais ... Brasília: Universidade de Brasília, 2006. 1 CD-ROM

TRZESNIAK, P. As dimensões da qualidade dos periódicos científicos e sua presença em um instrumento da área da educação. Revista Brasileira de Educação, v. 1 1, n.32, p. 346-361, 2006.

WEITZEL, S.R. Fluxo da informação científica. In: POBLACIÓN, D.A.; WITTER, G.P.; SILVA, J.F.M. (org.). Comunicação \& produção científica: contexto, indicadores e avaliação. São Paulo: Angellara, 2006. p. 81-114.

WILLINSKY, J. The access principle: the case for open access to research and scholarship. Cambridge, MA: The MIT Press, 2006. 
PORTAL DE PERIÓDICOS CIENTÍFICOS LISTA DE VERIFICAÇÃO PARA MIGRAÇÃO - SEER/OJS

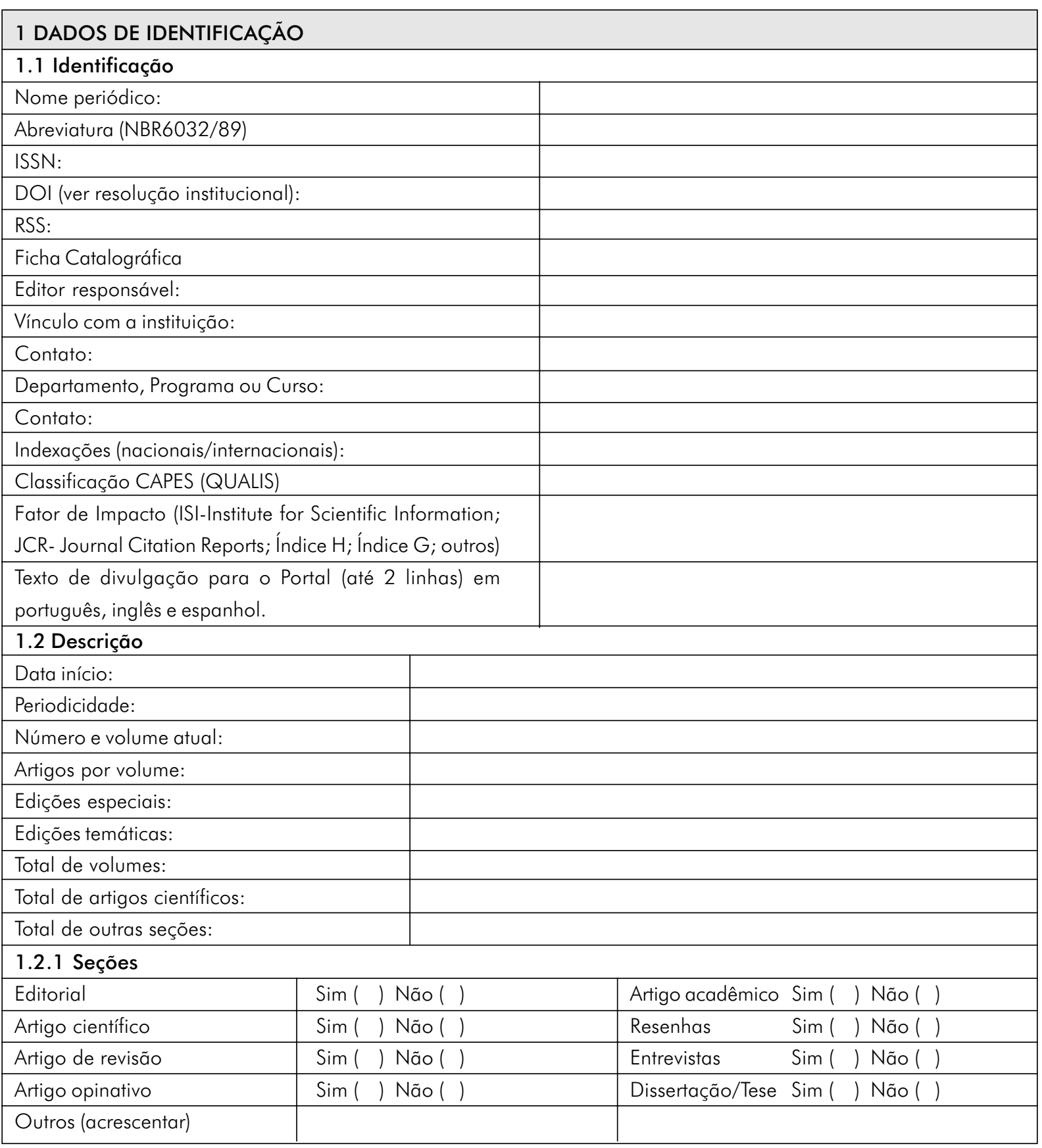

\section{DIMENSÕES DE QUALIDADE}

2.1 Técnico-normativa - conformidade com Associação Brasileira de Normas Técnicas (ABNT) ou outra, desde que citada e referenciada no periódico: (Obs.: Identificar cada tópico com sim ou não (necessária a padronização de acordo com cada periódico e sua área da atuação) 


\section{ANEXO \\ PORTAL DE PERIÓDICOS CIENTÍFICOS LISTA DE VERIFICAÇÃO PARA MIGRAÇÃO - SEER/OJS}

Continuação

\begin{tabular}{|c|c|c|}
\hline Número & Data & Título \\
\hline NBR6021 & $(5 / 2003)$ & Publicação periódica científica impressão - Apresentação \\
\hline NBR6022 & $(5 / 2003)$ & Artigo em publicação periódica científica impressa - Apresentação \\
\hline NBR6023 & $(8 / 2002)$ & Referências - Elaboração \\
\hline NBR6024 & $(5 / 2003)$ & Numeração progressiva das seções de um documento escrito - Apresentação \\
\hline NBR6025 & $(9 / 2002)$ & Revisão de originais e provas \\
\hline NBR6027 & $(5 / 2003)$ & Sumário - Apresentação \\
\hline NBR6028 & $(11 / 2003)$ & Resumo - Apresentação técnico-científica \\
\hline NBR6032 & $(8 / 1989)$ & Abreviação de títulos de periódicos e publicações seriadas \\
\hline NBR6034 & $(12 / 2004)$ & Índice - Apresentação \\
\hline NBR 10520 & $(8 / 2002)$ & Citações em documentos - Apresentação \\
\hline NBR 10525 & $(3 / 2005)$ & Número Padrão Internacional para Publicações Seriadas - ISSN \\
\hline NBR 10526 & $(10 / 1988)$ & Editoração de traduções \\
\hline NBR 10719 & $(8 / 1989)$ & Apresentação de relatórios técnico-científicos \\
\hline TB49 & $(1967)$ & Terminologia de documentos \\
\hline \multicolumn{3}{|c|}{ 2.2 Responsabilidade do periódico } \\
\hline \multicolumn{3}{|c|}{ Vínculo Institucional - mais apoios externos e financiadores } \\
\hline \multicolumn{3}{|c|}{ Missão - ênfase na perenidade do periódico } \\
\hline \multicolumn{3}{|c|}{ Política, regulamentos e mecanismos de seleção de editores, pareceristas e ad hoc } \\
\hline \multicolumn{2}{|c|}{$\begin{array}{l}\text { Comissão/Conselho/ } \\
\text { Corpo editorial }\end{array}$} & $\begin{array}{l}\text { Qualificação, diversidade geográfica e institucional - colocar link para o } \\
\text { Currículo Lattes }\end{array}$ \\
\hline \multicolumn{2}{|c|}{ Pareceristas ad hoc } & Qualificação e diversidade geográfica e institucional; incluir relação na página \\
\hline \multicolumn{2}{|c|}{ Revisão de pares } & $\begin{array}{l}\text { Definir políticas (fundamentais para a validação da informação científica; atender } \\
\text { as áreas de atuação e vínculo institucional }\end{array}$ \\
\hline \multicolumn{3}{|c|}{2.3 Informações ao público } \\
\hline \multicolumn{3}{|c|}{ Política do periódico e tipos de trabalhos que podem ser submetidos } \\
\hline \multicolumn{3}{|c|}{ Indexações e posicionamento nos rankings (CAPES) } \\
\hline \multicolumn{3}{|c|}{$\begin{array}{l}\text { Critérios de avaliação de artigos - fundamental para obtenção de indexação em fontes referenciais; de preferência } \\
\text { publicar formulário. }\end{array}$} \\
\hline \multicolumn{3}{|c|}{$\begin{array}{l}\text { Publicação das instruções aos autores - fundamental para obtenção de indexação em fontes referenciais; os artigos } \\
\text { publicados deverão estar em conformidade com as instruções. }\end{array}$} \\
\hline \multicolumn{3}{|c|}{ Explicitar as normas utilizadas com exemplos } \\
\hline \multicolumn{3}{|c|}{ Metadados - definidos pelo editor (revisados pelo editor) ou Comissão editorial. } \\
\hline \multicolumn{3}{|c|}{ Contato (eletrônico e local / físico) } \\
\hline \multicolumn{3}{|c|}{ 2.4 Periodicidade } \\
\hline \multicolumn{3}{|c|}{ Divulgação das datas de publicação de cada fascículo } \\
\hline \multicolumn{3}{|c|}{ Divulgação das datas de submissão de trabalhos } \\
\hline \multicolumn{3}{|c|}{ Fluxo do processo editorial e previsão de retorno aos autores } \\
\hline
\end{tabular}

TransInformação, Campinas, 22(1):33-45, jan./abr., 2010 
PORTAL DE PERIÓDICOS CIENTÍFICOS LISTA DE VERIFICAÇÃO PARA MIGRAÇÃO - SEER/OJS

Conclusão

\section{CRONOGRAMA}

Previsão dos artigos e volumes no portal (detalhar). Especificar quando coleções impressas, digitais (HTML, PDF, DOC, ZIP, outros) ou ambas.

\begin{tabular}{|l|c|c|c|}
\hline $\begin{array}{l}\text { 3.1 Atividades migração } \\
\text { Todos os artigos em versão PDF (Adobe Acrobat) e identificados } \\
\text { autor, volume, número, data de publicação, numeração de páginas }\end{array}$ & Quantidade & $\begin{array}{c}\text { Responsável } \\
\text { Editor }\end{array}$ & Prazo \\
\hline
\end{tabular}

\begin{tabular}{|c|c|c|c|}
\hline & Quantidade & Responsável & Prazo \\
\hline $\begin{array}{l}\text { Referências completas de todos os artigos em ABNT ou ISO ou } \\
\text { outra conforme a área } \\
\text { Planilha dados dos autores: nome, e-mail, vínculo institucional } \\
\text { na época da publicação, link Lattes, demais informações } \\
\text { necessárias - garantia de padronização do sistema } \\
\text { Relação dos sumários de todos os números com indicação } \\
\text { páginas } \\
\text { Textos aprovados pela comissão editorial para: } \\
\text { - Foco e escopo } \\
\text { - Políticas de Seção } \\
\text { - Processo de Avaliação por pares } \\
\text { - Periodicidade } \\
\text { - Política de Acesso Livre } \\
\text { - Submissões on-line } \\
\text { - Diretrizes para os autores } \\
\text { - Declaração de Direito Autoral } \\
\text { - Política de Privacidade } \\
\text { - Patrocínio } \\
\text { - Mapa do Portal } \\
\text { - Sobre o SEER } \\
\text { - Estatísticas (divulgar a configuração - estatísticas disponíveis) }\end{array}$ & & $\begin{array}{l}\text { Editor } \\
\text { Editor } \\
\text { Editor } \\
\text { Editor }\end{array}$ & \\
\hline
\end{tabular}

Fonte: Adaptado de Trzesniak, (2006); Medeiros et al. (2008) e Rodrigues e Fachin (2008). 
